University of Nebraska - Lincoln

DigitalCommons@University of Nebraska - Lincoln

USDA National Wildlife Research Center - Staff Publications
U.S. Department of Agriculture: Animal and Plant Health Inspection Service

July 2006

\title{
Effectiveness of a Motion-Activated Laser Hazing System for Repelling Captive Canada Geese
}

\author{
Scott J. Werner \\ USDA-APHIS-Wildlife Services, scott.j.werner@aphis.usda.gov \\ Larry Clark \\ USDA APHIS, larry.clark@aphis.usda.gov
}

Follow this and additional works at: https://digitalcommons.unl.edu/icwdm_usdanwrc

Part of the Environmental Sciences Commons

\footnotetext{
Werner, Scott J. and Clark, Larry, "Effectiveness of a Motion-Activated Laser Hazing System for Repelling Captive Canada Geese" (2006). USDA National Wildlife Research Center - Staff Publications. 126. https://digitalcommons.unl.edu/icwdm_usdanwrc/126
}

This Article is brought to you for free and open access by the U.S. Department of Agriculture: Animal and Plant Health Inspection Service at DigitalCommons@University of Nebraska - Lincoln. It has been accepted for inclusion in USDA National Wildlife Research Center - Staff Publications by an authorized administrator of DigitalCommons@University of Nebraska - Lincoln. 


\title{
Effectiveness of a Motion-Activated Laser Hazing System for Repelling Captive Canada Geese
}

SCOTT J. WERNER, ${ }^{1}$ United States Department of Agriculture, Animal and Plant Health Inspection Service, Wildlife Services, National Wildlife Research Center, Fort Collins, CO 80521-2154, USA

LARRY CLARK, United States Department of Agriculture, Animal and Plant Health Inspection Service, Wildlife Services, National Wildlife Research Center, Fort Collins, CO 80521-2154, USA

\begin{abstract}
Effective management techniques are needed to disperse Canada geese (Branta canadensis) and reduce the human-wildlife conflicts associated with high population densities. We evaluated the effectiveness of a motion-activated laser hazing system for repelling captive Canada geese. The system decreased occupancy of 8 pairs of geese on the treated subplot by $83 \%$ during habituation trials. When an additional pair of geese were added to the experiment, occupancy of the treated subplot decreased $>92 \%$ during each of the 20 nights of the extended habituation test. Avoidance (conditioned during the test) remained $<80 \%$ of pretreatment levels during the 2 days immediately following the habituation test but extinguished 3 days subsequent to the permanent inactivation of the laser hazing system. The motionactivated laser hazing system effectively repelled Canada geese in captivity. Additional field research is needed to determine the spatial extent of the laser hazing system and the effectiveness of the Doppler radar motion detector for repelling wild geese. (WILDLIFE SOCIETY BULLETIN $34(1): 2-7 ; 2006)$
\end{abstract}

\section{Key words}

behavioral extinction, Branta canadensis, Canada geese, Doppler radar motion detector, habituation, human-wildlife conflicts, nonlethal dispersal, repellent system, wildlife damage management.

Overabundant wildlife populations have been associated with numerous human-wildlife conflicts in the United States (Conover et al. 1995). Canada geese (Branta canadensis) populations in North America have increased dramatically during the past 30 years (Ankney 1996). Localized overabundant Canada geese populations have increased the number of human-wildlife conflicts and magnified their intensity.

Among 6,741 aircraft strikes reported from 1991-1998, the average cost per strike was greatest (\$36,735 [U.S.] per strike) among those involving geese (Dolbeer et al. 2000). Grazing by Canada geese can negatively impact wheat production (Flegler et al. 1987) and growth of rye (Conover 1988) during winter. Canada goose conflicts in the eastern United States include intensive foraging and localized (aquatic and terrestrial) fecal contamination at recreational areas (Conover and Chasko 1985). The close proximity of geese and humans increases risk associated with pathogenic bacteria prevalent in Canada goose feces (Kullas et al. 2002).

Several management alternatives have been used to reduce Canada geese related human-wildlife conflicts in the United States. These alternatives include aversive stimuli (Heinrich and Craven 1990, Aguilera et al. 1991), nonlethal chemical repellents (Cummings et al. 1995, Dolbeer et al. 1998), trapping, physical exclusion, hunting, and reproductive inhibition (Converse and Kennelly 1994). Among these management alternatives, most managers $(57 \%, n=68)$ who deal with nuisance Canada geese prefer nonlethal deterrents to manage goose conflicts (Conover and Chasko 1985). Support for lethal management alternatives increases when geese cause serious damage, lethal methods are the only viable means of control, and humane disposition is employed (Coluccy et al. 2001).

Lasers have been used to effectively frighten birds in Europe

${ }^{1}$ E-mail: scott.j.werner@aphis.usda.gov
(Briot 1996, Soudat-Soucaze and Ferri 1997) and North America. Low- and moderate-powered lasers have been used to disperse double-crested cormorants (Phalacrocorax auritus) from their night roosts near Mississippi catfish farms (Glahn et al. 2000) and Canada geese from urban areas (Sherman and Barras 2004). Controlled experiments recently have shown that such hand-held lasers also can effectively repel Canada geese, mallards (Anas platyrhynchos), and rock doves (Columba livia) from treated areas within test cages (Blackwell et al. 2002).

In contrast to manual activation, demand-performance (e.g., radar-activated) hazing systems could provide continuous repellent consequences contingent upon the activity of a target subject (Stevens et al. 2000). Such automated systems would alleviate the need for continuous presence of personnel for operation. The consistency and the interval of the performance-consequence association affect resultant behaviors (Muller et al. 1979, Tanimoto et al. 2004). Thus, motion-activated hazing systems may be more effective at mitigating wildlife damage than manually activated, periodic, and random-delivery repellent systems (e.g., propane cannons with a fixed or random consequence-consequence interval).

We evaluated the effectiveness of a motion-activated laser hazing system for repelling captive Canada geese. In particular we were interested in evaluating the effects of repeated exposure (i.e., habituation) and subsequent inactivation of the laser hazing system (i.e., behavioral extinction).

\section{Methods}

\section{Testing Facilities}

We conducted this study at the United States Department of Agriculture's National Wildlife Research Center (NWRC) in Fort Collins, Colorado, United States. We captured 18 Canada geese in February 2003 using a cannon net (Dill and Thornsberry 1950) 
in northern Colorado, United States. We sexed captured geese by cloacal examination (United States Fish and Wildlife Service and Canadian Wildlife Service 1977). We quarantined geese and held them within individual cages at the NWRC Outdoor Animal Research Facility for at least 2 weeks prior to the study. We randomly assigned 2 groups of 2 geese ( 1 male and 1 female) to plots within an open building adjacent to the holding facilities for subsequent testing. We replicated testing with 8 goose pairs and tested 2 pairs concurrently. Each of 2 plots (each $11 \times 17 \mathrm{~m}$ ) was divided into 2 subplots using a $1.5-\mathrm{m}$ high visual screen extended through a portion of the plot middle (i.e., geese could move freely between subplots; Fig. 1). We acclimated goose groups within plots for 6 days prior to the treatment.

\section{Hazing Device}

The motion-activated laser hazing system (Avian Systems Corporation, Louisville, Kentucky) was comprised of a Doppler radar motion detector $(10.5 \mathrm{GHz}$ microwave) and a rotating red diode laser ( $650 \mathrm{~nm}, 68 \mathrm{~mW}, 76-\mathrm{mm}$ beam diameter at source). The motion detector simultaneously transmitted and received reflected signals from objects within its parabolic field of view. Stereo Doppler used 2 receiving channels to detect the distance moved rather than the size and speed of the subject. The range of the Doppler detector was approximately $10-15 \mathrm{~m}$ for a single bird and $20-25 \mathrm{~m}$ for a flock of birds. The activation of the laser was randomized based upon 1) thresholds of activity (i.e., aggregate distance of detected motion), 2) periods of rotation or oscillation, and 3) rotational direction to maximize the potential of the laser hazing system.

\section{Experimental Design}

This study consisted of 3 phases: pretreatment, treatment, and posttreatment. We replicated each phase with 8 pairs of wildcaught Canada geese ( $n=8$ nonbreeding, male-female pairs). Because the laser wavelength used in the study is most effective for dispersing Canada geese under low ambient light conditions (Blackwell et al. 2002), the purpose of the pretreatment was to train geese to occupy plot halves containing an automatic feeder (Specialty Systems, Incorporated, Austin, Texas) between approximately 1900 hours and 0600 hours throughout the study (i.e., during daily period of low ambient light). Sunrise and sunset occurred from 0529-0626 hours and 1934-2035 hours, respectively, during the study.

The pretreatment included presentation of high-energy food (i.e., whole corn and poultry grower mixture) from the automatic feeder in 1 subplot ("treated" plot half). We presented this food 3 times each night throughout the study: 30 min prior to sunset, 2400 hours, and $30 \mathrm{~min}$ prior to sunrise. We removed the highenergy food from test plots from 0800-1000 hours daily throughout the study. Each plot contained an untreated (control) subplot, opposite the treated plot half. We recorded goose occupancy within treated subplots during each phase of the study using infrared cameras, infrared spotlights, and video cassette recorders (Polaris Industries, Incorporated, Norcross, Georgia) that were capable of imaging goose behavior under the low ambient light conditions necessary for laser repellency $(<31 \times$; Blackwell et al. 2002). We marked individual geese with leg bands (males) or neck bands (females) painted with infrared-reflective paint (J. D. L. Industries, Incorporated, Miami, Florida) for subsequent video analyses. A maintenance diet (i.e., $6.25 \mathrm{~m}^{2}$ of grass sod in each subplot) and clean water were available ad libitum in each plot throughout the study (Fig. 1).

We placed the laser hazing device near the automatic feeder on a red box during the treatment and posttreatment such that the activated laser beam would be projected on the floor and adjacent subplot walls (Fig. 1). Thus, the activated laser did not necessarily shine directly into the eyes of geese within the treated subplot. The purpose of the treatment phase (i.e., habituation testing) was to determine the degree of place avoidance throughout an extended period of nightly exposure to laser hazing. The treatment phase included 5 nights for each of 8 pairs of geese. This phase was extended to 20 nights for a ninth pair to evaluate habituation throughout this prolonged and repeated exposure to laser hazing. We recorded goose occupancy of treated (laserhazed) subplots on video prior and subsequent to the remote activation of the automatic feeder (from 30 min prior to sunset to 30 min prior to sunrise during each day of the test). The laser hazing device was inactive from $\sim 0700-1800$ hours daily during habituation testing.

The purpose of the posttreatment (i.e., behavioral extinction testing) was to determine the persistence of place avoidance subsequent to the permanent inactivation of the laser hazing system. The behavioral extinction procedure involves presentation of a cue in the absence of laser activity (i.e., presence of the red box and the inactivated laser hazing system subsequent to habituation testing within the same subplot). The posttreatment included 6 nights for 8 goose pairs.

\section{Statistical Analyses}

The dependent measure for this study was goose occupancy $( \pm 1$ goose min) within treated subplots. We used descriptive statistics (mean $\pm \mathrm{SE}$ ) and a repeated measures analysis of variance (ANOVA; PROC Mixed, SAS 1999) to examine differences among subplot occupancy ( $n=8$ pairs) during the pretreatment, treatment, and posttreatment. The independent variables of the ANOVA were goose pairs (subject), study period (pretreatment, treatment, and posttreatment), study days (i.e., within or repeated measure), and the period-by-day interaction. We also used descriptive statistics to summarize the number of nightly laser activations during the 5-night habituation test and occupancy of the treated subplot throughout an extended period of nightly exposure to laser hazing (i.e., for 20 nights of habituation testing; $n=1$ pair).

\section{Results}

Geese spent $269( \pm 67)$ min on the "treated" subplot during the pretreatment phase of the experiment (Fig. 2). Time on the treated subplot decreased to $47( \pm 9)$ min during the treatment phase. This represented an $83 \%$ reduction in average goose occupancy of treated subplots $\left(F_{2,14}=6.30, P=0.01\right)$. We did not observe a study day effect $\left(F_{5,35}=1.15, P=0.35\right)$ or a period-byday interaction $\left(F_{9,53}=0.35, P=0.95\right)$.

Geese activated the laser device from 11 ( \pm 3.8 ; night 1$)$ to 17 ( \pm 4.9 ; night 4$)$ times per night during the treatment. Geese spent $237( \pm 54)$ min on the "treated" subplot during the posttreatment phase of the experiment (Fig. 2). Although average goose 


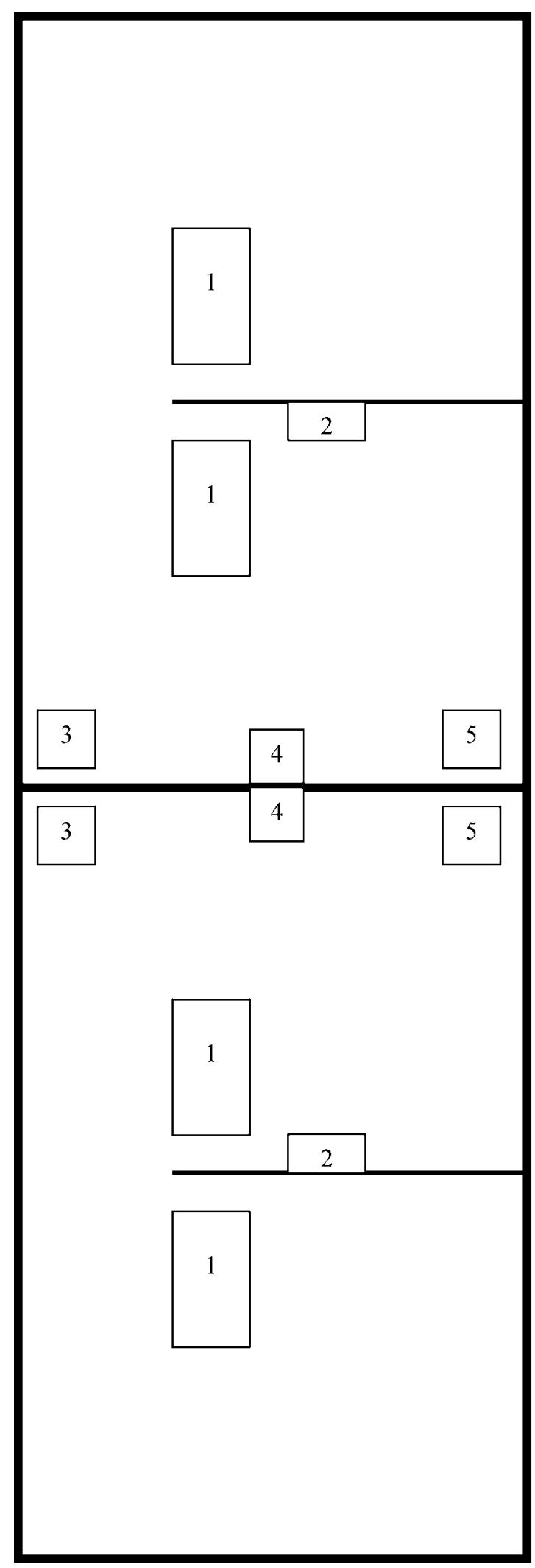

$1-6.25 \mathrm{~m}^{2}$ of grass sod

\section{2- Laser hazing device on red box}

3- Automatic feeder that dispensed mixture of whole corn and poultry grower $30 \mathrm{~min}$ prior to sunset, 2400 $\mathrm{hr}$, and $30 \mathrm{~min}$ prior to sunrise

4- Motion detector that activated laser hazing device

5- Infrared video camera used to measure goose occupancy within subplots associated with the laser hazing device prior to, during, and after the test

Figure 1. Behavioral conditioning scheme used to evaluate a motion-activated laser hazing system for repelling Canada geese in captivity. North and south plots $(11 \times 17 \mathrm{~m}$, each) were separated with 1.5-m high visual screen (bolded midline between plots). Plots were further divided into treated and control subplots using visual screen (indicated in Fig. as a partial line) extended through a portion of each plot middle. 


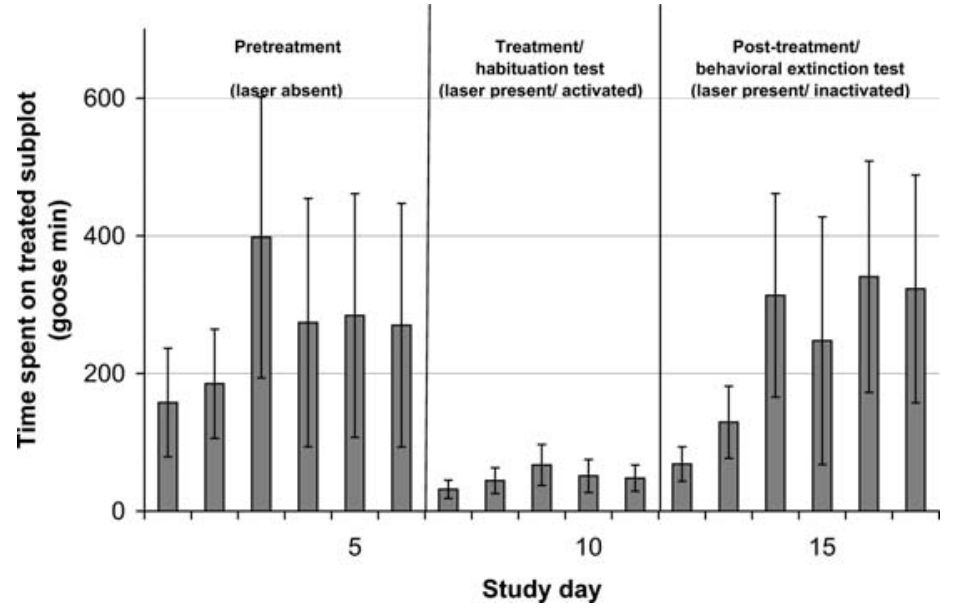

Figure 2. Average ( \pm SE) occupancy of Canada geese ( $n=8$ pairs) of the treated subplot prior to the test, and during habituation and behavioral extinction testing. The laser device was present and activated within treated subplots during the habituation test. The laser device was present and inactivated in treated subplots during behavioral extinction testing.

occupancy of treated subplots failed to return to $80 \%$ of pretreatment levels within 2 days following the treatment, the persistence of place avoidance (conditioned during the test) extinguished 3 days subsequent to the permanent inactivation of the laser hazing system (Fig. 2).

We also evaluated the potential for habituation to the laser with an additional pair of geese presented with the activated laser for 20 nights. These geese occupied the "treated" subplot an average of 266 (range $=50-1,120$ ) goose min during the pretreatment. This occupancy decreased to an average of 8 (range $=0-21$ ) goose $\mathrm{min}$ throughout the 20-night habituation test.

\section{Discussion}

The occupancy of captive Canada geese was effectively reduced within subplots associated with nocturnal activation of the laser hazing device. Moreover, this repellency resulted in a marked difference in the quality of grass sod associated with the lasertreated (Fig. 3A) and control (Fig. 3B) subplots subsequent to the 20 -day habituation test. Geese apparently did not habituate to the activated laser hazing system when they were exposed up to 20 consecutive nights. However, they returned to treated subplots within a few days after the laser system was inactivated. Thus, both the presence and activation of the hazing device were necessary for goose repellency.

Previous evaluations of lasers as wildlife repellents have provided mixed results. Manually activated red lasers $(633 \mathrm{~nm}, 10 \mathrm{~mW}$; and $650 \mathrm{~nm}, 68 \mathrm{~mW}$ ) have been used to disperse birds in captivity (Blackwell et al. 2002). In contrast, pulsating light (white, aircraft landing lights) and nonpulsating light do not apparently affect the reaction distance of brown-headed cowbirds (Molothrus ater), Canada geese, European starlings (Sturnus vulgaris), herring gulls (Larus argentatus), and mourning doves (Zenaida macroura; Blackwell and Bernhardt 2004). Similarly, the red lasers used by Glahn et al. (2000) to disperse cormorants were ineffective at dispersing American crows (Corvus brachyrbynchos; Gorenzel et al. 2002) during replicated field experiments. However, a $650 \mathrm{~nm}, 50$ $\mathrm{mW}$ diode laser effectively reduced goose numbers at night during a controlled field study in urban areas of Ohio (Sherman and Barras 2004). The reasons for these interspecific differences are unclear.

Retinal irritation and ocular hazards are not necessary for dispersal of birds with red lasers (Glahn et al. 2000). Comparative results from ophthalmic examinations and electroretinagrams prior and subsequent to exposure to a red laser $(633 \mathrm{~nm}, 5 \mathrm{~mW}$, $12-\mathrm{mm}$ beam diameter at source) suggested that no retinal degeneration or necrosis resulted from exposing the retina of 5 double-crested cormorants to the laser activated 1-33 m away (Glahn et al. 2000). Like irritants, however, the laser hazing device yielded "reflexive withdrawal" and persistent sampling of the treated subplot throughout habituation testing.

We have operationally defined primary repellency as that which evokes reflexive withdrawal or escape behavior in an animal (Werner and Clark 2003). In contrast, secondary repellents evoke an adverse physiological effect (e.g., illness, pain), which, in turn, is associated with a subsequently avoided sensory stimulus (e.g., taste, odor, visual cue; Clark 1997). Avoidance is characterized by discontinued sampling or consumption of foods and discontinued occupancy of places, previously associated with an aversive stimulus. Because the occupancy of the treated subplot and the activation of the laser device were never discontinued subsequent to laser exposure, the laser mode of action was consistent with primary repellency.

Blackwell et al. (2002) suggested that lasers produce a neophobic avoidance response to the approaching laser beam contrasted against a dark background. They hypothesized that the effectiveness of lasers as avian repellents was dependent on the species and behavioral ecology (e.g., diurnal, noctural) of the bird, the beam width and wavelength of the laser, and the context of the repellent application (e.g., escape potential in captive versus field trials). Additionally, the effectiveness of wildlife repellents is dependent upon our understanding of the 1) sensory modality that mediates the perception of the repellent signal, 2) relevant processes of animal learning, and 3) resultant, contextually appropriate circumstances for the repellent application (Werner and Clark 2003).

In contrast to manually activated repellent systems, a great asset of the evaluated hazing system was its Doppler radar motion detector. The activation threshold for a Doppler detector is adjusted based upon the distance that a target subject is required to move (e.g., 10-40 cm). Thus, vibrations and periodically moving objects are minimized as sources of false activations of the repellent system. Additional field research is needed to determine the 1) spatial extent of the evaluated laser hazing system, and 2) utility of Doppler radar motion detectors for repelling wild geese.

\section{Acknowledgments}

We thank Avian Systems personnel for their provision of 2 laser hazing systems and their technical support for this study. Dr. S. L. Werner provided expert consultation regarding the videography and motion analyses associated with this study. We especially appreciate the dedicated assistance and detailed video analyses provided by T. Saab, J. Gilman, G. Young, B. Nagamine, C. Giblet, J. Stamm, A. Englert, and T. Kingsley. S. K. Tupper and 

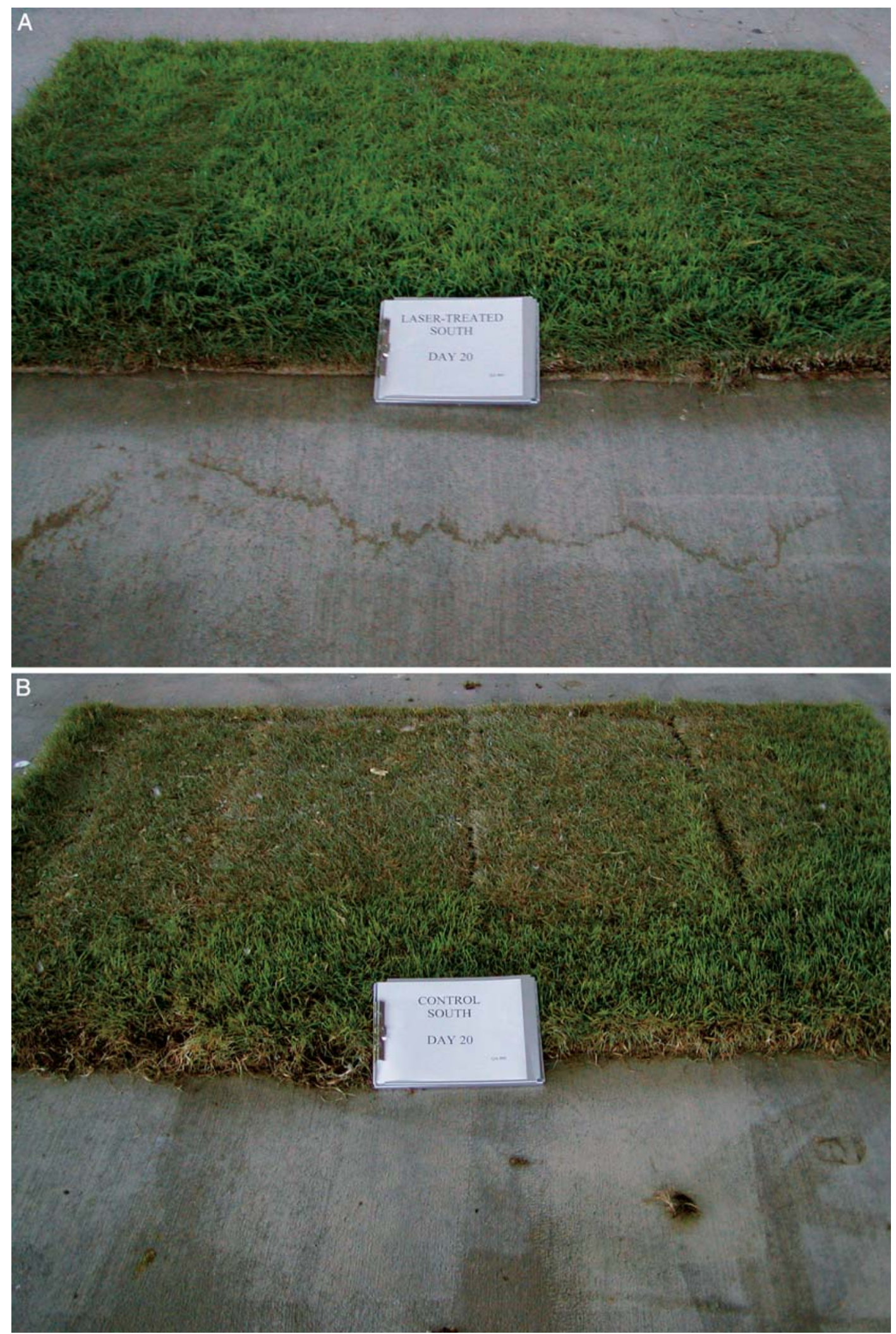

Figure 3. Grass sod from a laser-hazed (A) and control (B) subplot subsequent to the 20-day habituation test of a laser hazing system for repelling Canada geese.

Drs. R. C. Beason, B. F. Blackwell, and M. E. Tobin provided constructive feedback from their review of this manuscript. The care and use of animals associated with this study (NWRC Study Protocol QA960) were approved by NWRC's Institutional
Animal Care and Use Committee. This research was conducted under a Confidentiality Agreement with the laser hazing system manufacturer. Corporate collaborations do not imply endorsement by the United States Department of Agriculture. 


\section{Literature Cited}

Aguilera, E., R. L. Knight, and J. L. Cummings. 1991. An evaluation of two hazing methods for urban Canada geese. Wildlife Society Bulletin 19:32-35. Ankney, C. D. 1996. An embarrassment of riches: too many geese. Journal of Wildlife Management 60:217-223.

Blackwell, B. F., and G. E. Bernhardt. 2004. Efficacy of aircraft landing lights in stimulating avoidance behavior in birds. Journal of Wildlife Management 68 725-732.

Blackwell, B. F., G. E. Bernhardt, and R. A. Dolbeer. 2002. Lasers as nonlethal avian repellents. Journal of Wildlife Management 66:250-258.

Briot, J. L. 1996. Latest French experiments with lasers to frighten birds. Proceedings of the International Bird Strike Committee 23:345.

Clark, L. 1997. Physiological, ecological, and evolutionary bases for the avoidance of chemical irritants by birds. Current Ornithology 14:1-37.

Coluccy, J. M., R. D. Drobney, D. A. Graber, S. L. Sheriff, and D. J. Witter 2001. Attitudes of central Missouri residents toward local giant Canada geese and management alternatives. Wildlife Society Bulletin 29:116-123.

Conover, M. R. 1988. Effect of grazing by Canada geese on the winter growth of rye. Journal of Wildlife Management 52:76-80.

Conover, M. R., and G. G. Chasko. 1985. Nuisance Canada goose problems in the eastern United States. Wildlife Society Bulletin 13:228-233.

Conover, M. R., W. C. Pitt, K. K. Kessler, T. J. DuBow, and W. A. Sanborn. 1995. Review of human injuries, illnesses, and economic losses caused by wildlife in the United States. Wildlife Society Bulletin 22:407-414.

Converse, K. A., and J. J. Kennelly. 1994. Evaluation of Canada goose sterilization for population control. Wildlife Society Bulletin 22:265-269.

Cummings, J. L., P. A. Pochop, J. E. Davis, Jr., and H. W. Krupa. 1995. Evaluation of Rejex-It AG-36 as a Canada goose grazing repellent. Journal of Wildlife Management 59:47-50.

Dill, H. H., and W. H. Thornsberry. 1950. A cannon-projected net trap for capturing waterfowl. Journal of Wildlife Management 14:132-137.

Dolbeer, R. A., T. W. Seamans, B. F. Blackwell, and J. L. Belant. 1998. Anthraquinone formulation (Flight Control ${ }^{\mathrm{TM}}$ ) shows promise as avian feeding repellent. Journal of Wildlife Management 62:1558-1564.

Dolbeer, R. A., S. E. Wright, and E. C. Cleary. 2000. Ranking the hazard level of wildlife species to aviation. Wildlife Society Bulletin 28:372-378.

Flegler, E. J., Jr., H. H. Prince, and W. C. Johnson. 1987. Effects of grazing by Canada geese on winter wheat yield. Wildlife Society Bulletin 15:402-405.

Glahn, J. F., G. Ellis, P. Fioranelli, and B. Dorr. 2000. Evaluation of moderateand low-powered lasers for dispersing double-crested cormorants from their night roosts. Proceedings of the Eastern Wildlife Damage Management Conference 9:34-45.

Gorenzel, W. P., B. F. Blackwell, G. D. Simmons, T. P. Salmon, and R. A. Dolbeer. 2002. Evaluation of lasers to disperse American crows, Corvus brachyrhynchos, from urban night roosts. International Journal of Pest Management 48:327-331.

Heinrich, J. W., and S. R. Craven. 1990. Evaluation of three damage abatement techniques for Canada geese. Wildlife Society Bulletin 18:405410.

Kullas, H., M. Coles, J. Rhyan, and L. Clark. 2002. Prevalence of Escherichia coli serogroups and human virulence factors in faeces of urban Canada geese (Branta canadensis). International Journal of Environmental Health Research 12:153-162.

Muller, P. G., R. E. Crow, and C. D. Cheney. 1979. Schedule-induced locomotor activity in humans. Journal of the Experimental Analysis of Behavior 31:83-90.

SAS Institute. 1999. SAS/STAT User's Guide, Version 8. SAS Institute, Cary, North Carolina, USA.

Sherman, D. E., and A. E. Barras. 2004. Efficacy of a laser device for hazing
Canada geese from urban areas of northeast Ohio. Ohio Journal of Science 103:38-42.

Soudat-Soucaze, J. D., and M. Ferri. 1997. A means of scaring birds: the laser gun, description and applications to cormorants and other birds. Desman (c) S. A. R. L, France in cooperation with the Office for Wildlife Protection and Regulation of Hunting and Fishing, Modena Province Regione Emilia Romagna, Italy.

Stevens, G. R., J. Rogue, R. Weber, and L. Clark. 2000. Evaluation of a radaractivated, demand-performance bird hazing system. International Biodeterioration and Biodegradation 45:129-137.

Tanimoto, H., M. Heisenberg, and B. Gerber. 2004. Experimental psychology: event timing turns punishment to reward. Nature 430:983.

United States Fish and Wildlife Service and Canadian Wildlife Service. 1977. North American bird banding manual. Volume 2. United States Department of Interior, Washington, D.C, USA.

Werner, S. J., and L. Clark. 2003. Understanding blackbird sensory systems and how repellent applications work. Management of North American Blackbirds Symposium, Bismarck, North Dakota, USA.

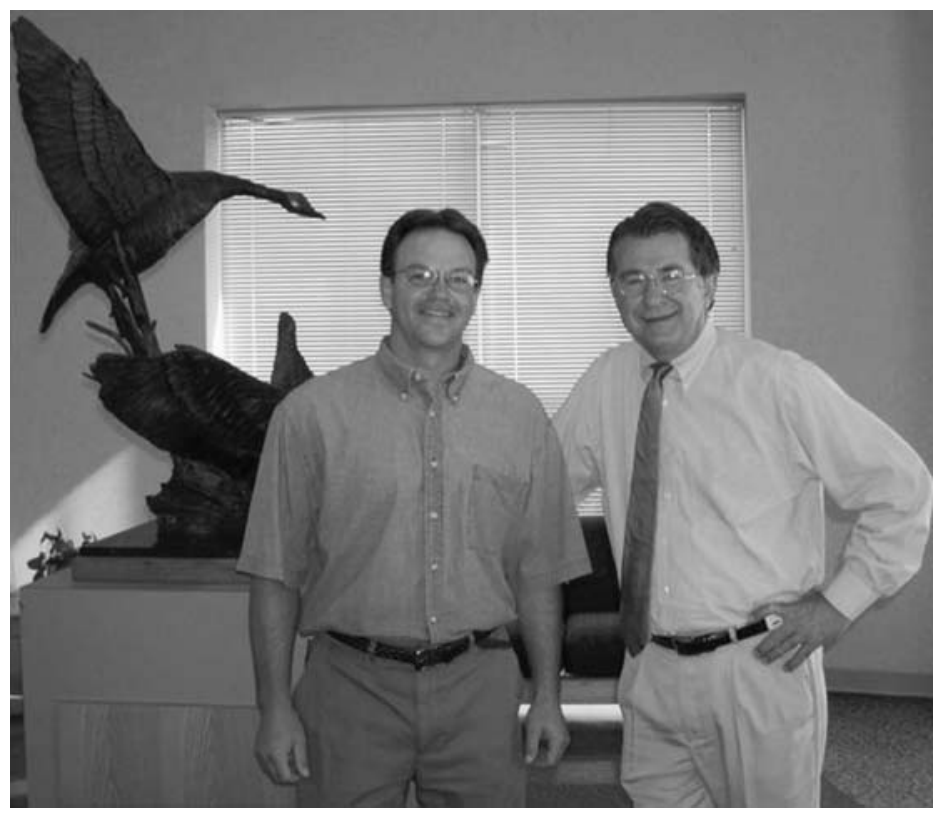

Scott Werner (left) is a Research Wildlife Biologist in the Bird Research Program of the National Wildlife Research Center (NWRC). Scott earned his B.S. in wildlife and fisheries science at Penn State University, and his M.S. and Ph.D. in range science at Utah State University. Scott's research interests include the physiological bases of food and habitat selection, and the development of non-lethal repellents for wildlife. Larry Clark (right) is the Assistant Director of the NWRC. Larry completed his B.S. in zoology from the University of Maryland, M.S. in biology from Northern Arizona University, and Ph.D. in evolutionary ecology and population biology from the University of Pennsylvania. His research interests include chemical ecology and sensory biology of vertebrates and wildlife disease ecology.

Associate editor: Haukos. 